\title{
Do Function Words Belong to Part of Speech?
}

\author{
Shara Mazhitayeva (Corresponding author) \\ Karaganda State University, 28 University Street, Karaganda, 100028, Kazakhstan \\ E-mail: shara.mazhitayeva@mail.ru \\ Zhanbai Kadyrov
}

North Kazakhstan State University named after Manash Kozybayev, Pushkin Street 86, Petropavlovsk, 150000, Kazakhstan

Zhandos Smagulov

Karaganda State University, 28 University Street, Karaganda, 100028, Kazakhstan

Kamshat Amanbaevna Toleubayeva

Karaganda State University, 28 University Street, Karaganda, 100028, Kazakhstan

Sagila Rahimberlina

Karaganda State University, 28 University Street, Karaganda, 100028, Kazakhstan

Received: 14-08-2016

Published: 10-12-2016
Accepted: 12-10-2016

doi:10.7575/aiac.ijalel.v.5n.7p.142 URL: http://dx.doi.org/10.7575/aiac.ijalel.v.5n.7p.142

\begin{abstract}
The term "function words" ("auxiliary part of speech") in traditional grammars of Kazakh and Russian languages have different connotations due to its functions. In foreign linguistics function words generally are not regarded in opposition to the traditional grammatical classes of words, although sometimes stand for relatively close category of words, which include articles, prepositions (postpositions) and conjunctions. In the 60-70 years of the twentieth century the function words in Kazakh language have sufficiently been investigated, but within the development of linguistics in the Kazakh according to some scholars the function words as a complex phenomenon suggested to regard them as a separate set of words. The theoretical significance of this article is the author's attempt to reveal the linguistic characteristics of function words in Kazakh language, to show their place in language, as well as to determine their nature as a part of speech.

Keywords. Function words, parts of speech, grammatical meaning, lexical meaning, auxiliary word, members of sentence

\section{Introduction}

Parts of speech is a class of words based on the word's function, the way they work in a sentence or it is defined as a linguistic category of words sharing syntactic or morphological behaviour and semantic properties. The parts of speech are classes of words, all the members of these classes have certain characteristics in common which distinguish them from the members of other classes. The problem of word classification into parts of speech still remains one of the most controversial problems in modern linguistics. The attitude of grammarians with regard to parts of speech and the basis of their classification varied a good deal at different times. Thus, each language has various number of word classes. For example, there are ten in Kazakh, Russian and English languages, twelve in German (Table 1; Table 2).
\end{abstract}

Table 1. Parts of speech in Russian and Kazakh languages (Akhmetzhanova Z.K., 1989; Mazhitayeva Sh., 2003)

\begin{tabular}{|c|c|c|}
\hline $\mathrm{N}$ & Russian language & Kazakh language \\
\hline 1 & Noun & Noun \\
\hline 2 & Adjective & Adjective \\
\hline 3 & Numeral & Numeral \\
\hline 4 & Pronoun & Pronoun \\
\hline 5 & Verb & Verb \\
\hline 6 & Adverb & Adverb \\
\hline 7 & Preposition & 7 function words: \\
\hline 8 & Conjunction & a) postpreposition \\
\hline 9 & Function words & $\begin{array}{l}\text { b) coordinating conjunctions; } \\
\text { c) function words }\end{array}$ \\
\hline \multirow[t]{3}{*}{10} & Interjections & 8 Interjections \\
\hline & & 9 Imitative words \\
\hline & & 10 modal words \\
\hline
\end{tabular}


The special part of speech in Kazakh language is auxiliary words (function words) which is subdivided into

1) function words:
a) post-preposition;
b) function words;
c) interjections;
d) auxiliary words;
e) auxiliary verbs.

Table 2. Classes of words in German and English languages (S. Mazhitayeva, 2003; V. Venjavskaja, 2009)

\begin{tabular}{lll}
\hline № & German & English \\
\hline 1 & das Substantiv & the Noun \\
\hline 2 & das Verb & the Verb \\
\hline 3 & das Adjektiv & the Adjective \\
\hline 4 & das Numerale & the Numeral \\
\hline 5 & das Pronomen & the Pronoun \\
\hline 7 & das Adverb & the Adverb \\
\hline 9 & das Modalwort & \\
\hline 10 & die Praeposition & the Preposition \\
\hline 11 & der Artikel & \\
\hline 12 & die Interjektion & the Interjection \\
\hline
\end{tabular}

Another class of words is - interjection; Imitative words - the ninth part of speech. The last group is modal words (Kazakh language grammar, 2002. p.440).

Parts of speech by prominent linguists V.V. Vinogradov, L.A.Bulakhovskye, L.V.Tsherba R.A.Budagov, A.M.Kononov, V.M.Zhirmunskye, A.Iskakov and others have been discriminated according to two criteria: lexical and grammatical groups.

The classical parts of speech theory goes back to ancient times. According to the classification of the parts of speech all words were divided into 3 parts: basic, categorematic words, auxiliary words (function words) and interjections (Salakhov R. A., 1999; Chomsky N., 1965; Andrew Carnie, 2011).

The development of function words and its grammatical function in modern Kazakh linguistics, is still far from being solved. However, this class of words mostly has been regarded from morphological angle in linguistic researches. In almost each grammars function words are regarded as a class of words that denote relations and connections between the notional words, and thus have no direct bearing on anything extra-linguistic, to form a new word.

Some approaches to the problem of function words were suggested by A.Baitursynov, K. Zhubanov, S.Amanzholov, M.Balakayev. Later, other scientists as F.Kenjebayeva, R.Amirov, K. Amiraliyev took into account their development history, meaning and function in a sentence, classification. The main function of function words and general features have been described in the works of K.Iskakova, K. Akhanov, N.Oralbayeva. However, in their works one cannot find the information about its types as a particular field for investigation. In this regard grammatical and specific features, the appropriate usage of function words have not also been covered.

The primary function is based on constructing the basic vocabulary and grammar of the language. The wealth and value of the Kazakh language enables it to fully function for describing the environment, society, natural phenomena or people's relationships with each other. In modern Kazakh language all classes of words are distinguished by semantic and morphological criteria. They are notional units and function words.

The lexical meaning of notional words is predominant that serves as a basis of communication in a certain content. According to grammar rules in speech they can form another word, can serve as an independent member. There are some ways of new word formation. Notional units are words that bear lexical and grammatical meanings by adding semantic coloring. As for function words they have no formal features and should be memorized as ready-made units.

One of the most specific features of the word is its indivisibility. As any other linguistic unit the word is a bilateral entity. It unites a concept and a sound image and thus has two sides - the content and expression sides: concept and sound form. 
These days there is an urgent issue to distinguish primary meaning of function words and its significance in the usage as it still requires careful study. It is one of the problems of functional grammar. Thus to systemize meanings and significance of function is very crucial. For example, function words are words that must be associated with another word or phrase to impart meaning, i.e., does not have its own lexical definition. In modern grammar function words express grammatical relationships with other words but that lack definite lexical meaning. The intensifying function of this class of words in Kazakh language has not been revealed yet.

From the beginning, function words were regarded as words that bear a lexical meaning. Last researches show that within the time it had lost its initial meaning, and created a new lexical and semantic group of function words. The main evidences of their usage can be seen in ancient Turkic runic inscriptions. From inscriptions dated back V-VIII centuries one can assume that the function words formed a separate category with specific value. In particular, the process of function words formation has been determined at the time of Orkhon-Yenisey writings. The process of new words formation from function words or its initial formation can be defined as the process of function words formation.

\section{Materials and methods}

Function words that have been found in the language of ancient Turkic writing monuments are regarded as the architypes of the function words. Traditional scientific descriptive method, contextual analysis, comparative approaches, synthesis, genetic study are of great importance in investigating the nature of function words.

In ancient Turkic languages function words were carefully studied as a separate part of speech and their origin, methods of formation, specific features in development greatly contribute in revealing the history of modern Turkic languages. If to compare function words in Turkic languages with other parts of speech it can be distinguished by its own specific features that make them unique. Previously we have mentioned that the development of function words as a separate part of speech dated back to ancient Turkic monuments.

\section{Results and Discussion}

As a categorical thing, function words have been developed since the time of ancient runic inscriptions of the OrkhonYenisey, Talas inscriptions. They went through a long process of linguistic formation as a derivative historical category. In modern Turkic languages affixes in some function words cannot be separated from the root, as it has become an integral part of the word unit.

Due to transposition approach (a term from the European tradition of linguistics for the change of category without any change in meaning; syntactic information and conceptual information are represented in structures that are linked but independent) when the affix is attached to the root to form function words. Function words have been derived from nominals or verbs that bear a definite meaning. This process is known at some stages of language development. Some nouns and verbs have rarely been used in their initial lexical meaning and obtain various grammatical meanings.

Function words generally have common features with those that can be found in Middles Ages, ancient and contemporary Turkic languages.

Participles as verb forms by adopting some characteristics of nominals changed into function words and gradually compiled into a large group of function words that function today in contemporary grammar as a part of speech.

In the second half of the nineteenth century for historical reasons different opinions and views on the nature of function words have been assumed amid scientists in the field of Turkology. However, until recently function words in runic writings have been regarded as a subject of scientific research.

According to the rules of dialectics nothing exists itself. Language exists within society and it is closely connected with its all spheres. The social development and its qualitative changes greatly impact on the structure of the language, development and classification.

Each part of speech has a different function in a sentence and differs from each other in its meaning, morphological features, word- formation and word-change and syntactical function. Parts of speech are characterized by specific and common features, interrelation, and the system of development. Kudaibergen Zhubanov has suggested the classification of words and it is considered to be a primary aspect in linguistic researches.

All the classes of words that exist today in modern grammar have been distinguished by Kudaibergen Zhubanov. The scholar first and foremost has identified three complex primary divisions of parts of speech: the root classes: nouns, adjectives, numerals, adverbs of time, verbs, and function words classes [K. Zhubanov, 1999. p.32]. In studying the formation of the parts of speech, one must consider morphological word formation and i.e. to pay attention to the ways of word formation. The materials of the Turkic languages have been taken for analyzing function words formation and ways of development. 
In investigating the nature of function words in Orkhon-Yenisey writings a great number of scientific works of S.E. Mallov (1951), V.M. Nassilov (1960), A.N. Kononov (1980), A. Nurmakhanova (1971), R. Amirov (1982), A.M. Tsherbak (1977), N. Hadjieminoglu (1992), G. Aidarov (1971) etc. and different concepts in ancient Turk and modern Turk languages have been taken as a basis.

Function words as a part of speech have appeared after a class of nominals. But it still requires to study whether this concept is typical for all languages or only for some of them. Generally a common value and its definitions in Turkic languages have been systematized in a certain extent.

In particular, according to commonly accepted theoretical principles confirmed by scientists, function words are a complex class of words that still requires careful study. Initially they served as meaningful words which gradually lost their meanings and comprised a new lexical and semantic group. One piece of evidence is that one can observe a great stock of function words in ancient Turkic runic inscriptions. The features in formation of function words, ways of development made us to conclude that the study of this class of words since the time of ancient Turkic history gives an opportunity to reveal the nature of function words in modern linguistics.

Gradual historical development of the parts of speech in the language can be clearly seen on the sample of function words. In Turkic languages the function words as an independent class of words have been developed later in comparison with others. They went through different changes in its formation and grammar structure as well. Thus they created a new group of words within grammar aspect due to their unique characteristics.

Each part of speech bears a specific common categorical meaning. In different languages each word has its own meaning and name. Therefore lexical and grammatical groups of words are differentiated by common categorical meaning and characteristics that they share within a class of words. The word combines in its semantic structure two meanings: grammatical and lexical. For function words its grammatical meaning dominates over the lexical one. As they have no references of their own in the objective reality; function words are only used as grammatical means to form frame utterances. It is one of the primary differences of function words between other classes of words.

To be independent as a categorical class it greatly depends on the forms of nominals and verbs. Through its long history of development they got lost the quality to convert a new word and turned into 'dead' form. By means of transposition, function words comprised a new class of words that had been derivated from various parts of speech. The study of the function words in ancient Turk runic inscriptions made by M.A. Kazem-Bek (1869; 1839), P. Melioranskye (1894), M. Terentyev (1875) gives the lexical and grammatical description, the history of formation of the class of words backed up with scientific findings.

According to the scientists, auxiliary words are not made of new words. "Function words - words that bear 'weak' lexical meanings, thus the grammatical meanings dominate over the lexical ones". We fully agree with the view of A. Iskakov who strongly believes that this type of auxiliary words can express a variety of grammatical relations and serve for different grammatical functions as well (Iskakov A., 1991. p.126).

Moreover, there is a wide range of concepts relating to function words as a separate word class. In general linguistics, like a variety of different notions, parts of speech dated back to ancient antique era. There is an opinion that parts of speech in reference to nominals and verbs were first mentioned in the IV century BC. For example, S.Mukhtarov has noticed 'Hindi is a language of a long history that well depicted in the work of Panini who lived in the fourth century BC'. Panini, in his work he provides a complete system of Sanskrit and for the first time distinguished parts of speech. His followers Yaska, Vavarugi, Katyayana, Patanjali accompanied with Katyaanna Patanjali. The scholars singled out four groups: "Noun (naman), Verb (akhyata), Auxiliary words (preposition - unasarga), and Function words (nipata)" (Mukhtarov S., 1999. p.6). This fact shows that function words as a separate word class was discriminated at that time.

Panini built virtually the whole structure of the Sanskrit language. Starting with about 1700 basic elements, put them into classes. The scholar had many followers as we mentioned above (Yaska, Vavarugi, Katyayana, Patanjali). K.Zhubanov: '... they discriminated four word clases: Nominals (naman), Verbs (akhyata), Function words (unasarqa) and Particles (nipata)'. They have distinguished function words as a separate group of words (Zhubanov K., 1999. p.6). In this regard S.Issayev has noted that according to Altai descendants view "... the emergence of abstract words coincide with the era of complex words" (Issayev S., 1998. p.11) Meanwhile, M.Orazov has distinguished three stages in historical development of Kazakh language (Kaidarov A., Orazov M., 1985). The first is the 'prehistoric time' or 'Altai era' so called by N.A. Baskakov's reflections (Baskakov N.A., 1969).

In the sentence function words serve as coordinators, time and place relators, express certainty and other different emotional coloring and signal the structural relationships between words to combine sentences. According to the semantic function they are divided into particles, postpositions, conjunctions are classified into three parts. For example, a conjunction is a word which joins two words, or sentences. This is also called sentence linker or connective. Their main task is to link two or more words, clauses or sentences. There are coordinating (combine two sentences which are independent of each other), subordinating (joins two sentences which are totally dependent on each other) correlative conjunctions (a paired conjunction and it works only with pairs). Particle is mostly used for words that help to encode grammatical categories (such as negation, mood or case), or fillers or discourse markers that facilitate discourse. 
Generally in linguistics the function words is a part of speech which cannot be inflected, declined or conjugated. They must be associated with another word or phrase in order to impart a meaning. They mainly serve to express grammatical relationship between words in a sentence. In Kazakh linguistics the function words can be distinguished by these concepts.

\section{Conclusion}

Thus, if to conclude in Kazakh linguistics function words refer to a separate part of speech that fails to bear lexical meaning. They cannot serve as principal parts of the sentence due to their 'weak' or zero lexical meaning. In Kazakh language the function words fail to change their grammatical form either. The function words separately or in the sentence have a subsidiary function.

In addition, in Kazakh linguistics each word class to make a certain group of words must have at least several outstanding characteristics to establish: bear lexical meanings of words, to be converted to serve as a member of the sentence and etc.

In Kazakh linguistics function words are a word class that has no lexical meaning or little lexical meaning or have ambiguous meaning and thus fail to serve as a member of sentence, mentioned characteristics cannot be used separately. At the same time, function words in Kazakh language might not be inflected. Function words serve to express grammatical relationships with other words within a sentence, or specify the attitude or mood of the speaker. They signal the structural relationships that words have to one another and are the bond that holds sentences together. To conclude, they serve as important elements to build the structure of sentence.

Therefore, taking into account the linguistic principles of new branches in contemporary grammar of Kazakh linguistics, we may assume that function words belong to a separate word class that are recognized as auxiliary words which serve to express grammatical relationships with other words within a sentence. Definitely, function words in Kazakh language evoke a lively debate amid scholars and time will show how right we are.

\section{References}

Aidarov G. (1971). Language of Orkhon monuments in ancient Turkic writings YIII c. Almaty: Science of the Kazakh SSR.

Akhmetzhanova Z.K. (1989). Principals of comparative fuctional research of Kazakh and Russian languages. Dissertation on obtaining academic degrees of doctor of philological sciences. Institute of linguistics Academy of Sciences of the Kazakh SSR. Almaty, p. 52.

Amirov R. (1982). The origin of disjunctive language. Almaty: Almaty Mektep.

Andrew Carnie, (2011). Modern Syntax. A Coursebook. Cambridge: University Press, p. 359.

Baskakov N.A. (1969). Introduction to the study of Turkic languages. Moscow: Sciences, p. 221.

Chomsky N.,(1965). Aspects of the Theory of Syntax. Cambridge, Massachusetts: MIT Press, p. 131.

Hadjieminoglu N. (1992). Türk Dilinde Edatlar (Adverbs in Turkish language). Istanbul: Milli Egitim Basimevi, p. 133ar.

Iskakov A. (1991). Modern Kazakh language. Morphology. Almaty: Ana tili, p. 382.

Issayev S. (1998). Grammatical features of words in Modern Kazakh language. Almaty: Science, p. 152.

Kaidarov A., \& Orazov M. (1985). Introduction to turkology. Almaty: Almaty Mektep.

Kazakh language grammar. (2002). In E.Zhanpeisov (Eds.). Astana, p. 784.

Kazem -Bek M.A. (1869). Grammar of Altai language. S.-Petersburg: Publisher St. Petersburg University.

Kazem -Bek M.A. (1839). Common grammar of Turkish and Tatar language. S.-Petersburg: Publisher St. Petersburg University.

Kononov A.N. (1980). The grammar of Turkic languages in runical monuments (YII-IX cc). Leningrad: Sciences.

Mallov S.E. (1951). Monuments of ancient Turkic writings. Moscow-Leningrad: Publishing House of the Academy of Sciences of the USSR, p. 451.

Mazhitayeva Sh. (2003). Comparative grammar of Kazakh and foreign languages. Karaganda: Publishing house of Karaganda SU, p. 109.

Melioranskye P., (1894). A short grammar of Kazakh and Kirgiz languages. S-PetersburgЖ Book on demand.

Mukhtarov S., (1999). The theory of parts of speech formation in Kazakh language linguistics. Dissertation results on obtaining academic degrees of candidates. . Institute of linguistics at Academy of Sciences of the Kazakh Republic. Almaty. $130 \mathrm{p}$.

Nassilov V.M. (1960). The language of Orkhon Enissey monuments. Moscow: Publishing house of east literature, p. 87.

Nurmakhanova A.N. (1971). Comparative grammar of Turkic languages. Almaty: Gylym.

Salakhov R. A., (1999). Practical grammar of German. Moscow: Metatext, p. 232.

Terentyev M. (1875). Grammar of Turkish, Persian, Kirgiz and Uzbek languages. S.-Petersburg: Printing of the Imperial Academy of Sciences.

Tsherbak A.M. (1977). Essays on comparative morphology of Turkic languages. Leningrad: Science.

Venjavskaja V.M., (2009). Grammar of English. Rostov na Donu: Fenix, p. 319.

Zhubanov K. (1999). Researches on Kazakh language. Almaty: Science, p. 362. 